Letter to the Editor

\title{
I ntravitreal injection does not change anterior chamber morphology on anterior segment optical coherence tomography
}

\author{
Alp Atik FRANZCO, Sanjeewa S. Wickremasinghe FRANZCO, Sukhpal S. Sandhu \\ FRANZCO and Ghee S. Ang FRANZCO
}

Royal Victorian Eye and Ear Hospital, 32 Gisborne Street, East Melbourne VIC 3066, Australia

Correspondence: Alp Atik, 52 Coxs Road, East Ryde NSW 2113, Australia alp.atik@mail.harvard.edu

Received 13 March 2019; accepted 14 March 2020

Funding sources / Financial disclosure: None

Conflict of interest: None

This is the author manuscript accepted for publication and has undergone full peer review but has not been through the copyediting, typesetting, pagination and proofreading process, which may lead to differences between this version and the Version of Record. Please cite this article as doi: 10.1111/ceo.13752

This article is protected by copyright. All rights reserved. 
Intravitreal injections (IVIs) are considered a safe treatment modality in posterior segment disease (1). Though complications are rare, IVI may cause raised intraocular pressure (IOP) (1). Therefore, we aimed to assess whether increases in vitreous pressure associated with IVI may lead to conformational changes in angle anatomy and thus increase the risk of sustained IOP rise. Anterior segment optical coherence tomography (AS-OCT) is a non-contact, non-invasive tool to assess the structures of the anterior segment and is sensitive in detecting angle closure (2). Thus, in the present study we evaluated the AS-OCT changes in the angle anatomy of eyes prior to and following IVI.

Thirty eyes of 25 patients received intravitreal injection of $0.05 \mathrm{~mL}$ aflibercept or ranibizumab. IOP was measured with iCare Rebound tonometer (Tiolat Oy, Helsinki, Finland) immediately before and after injection. Axial length and anterior chamber depth were measured with IOL Master 700 (Carl Zeiss Meditec, CA, USA) prior to injection. AS-OCT images were obtained using Visante OCT (Visante Model 1000; Carl Zeiss Meditec, CA, USA) at baseline and within 5 minutes of intravitreal injection. The AS-OCT imaging was performed at the horizontal meridian $\left(0^{\circ}\right.$ to $180^{\circ}$ scan line). All images were obtained under identical light conditions by the same examiner. The study received Institutional Ethics Approval (HREC reference $13 / 1129 \mathrm{~h}$ ) and conforms to the provisions of the Declaration of Helsinki.

The nasal and temporal quadrants for all eyes were measured by one observer (GSA), who selected locations of the scleral spur and iris recess apex to allow calculation of the anterior chamber parameters by the in-built software. These parameters were: angle opening distance (AOD), trabecular-iris space area (TISA) at 500 and $750 \mu \mathrm{m}$ from the scleral spur and scleral spur angle (SSA) for both the nasal and temporal quadrants (Figure 1). 


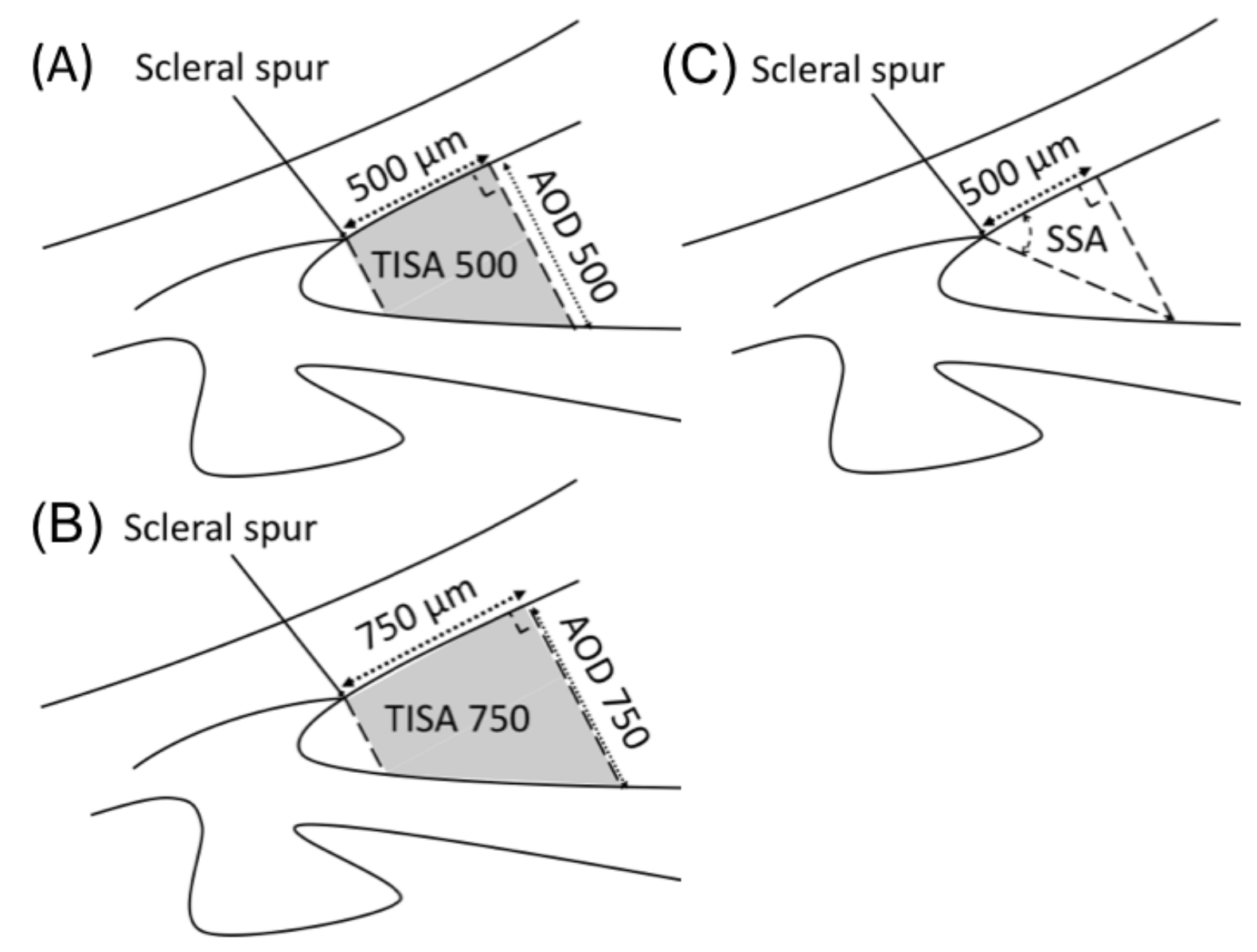

Figure 1: Schematic representation of the anterior segment optical coherence parameters. (a) Angle opening distance (AOD) and trabecular-iris space area (TISA) 500um from the scleral spur. (b) AOD and TISA 750um from the scleral spur. (c) Scleral spur angle (SSA).

Baseline characteristics of the patients are summarised in Table 1. 
Age (Years \pm SD)

Gender

$\begin{array}{rr}\text { Male (\%) } & 20(66.7) \\ \text { Female (\%) } & 10(33.3)\end{array}$

Race

Lens status

$$
\begin{array}{rr}
\text { White (\%) } & 22(88) \\
\text { Asian (\%) } & 3(12)
\end{array}
$$

$\begin{array}{rc}\text { Phakic (\%) } & 23(76.7) \\ \text { Pseudophakic (\%) } & 7(23.3) \\ \text { Axial length (mean } \pm \text { SD) } & 23.05 \pm 1.23\end{array}$

Table 1: Baseline characteristics of patients

Mean \pm SD IOP before injection was $13.72 \pm 3.98 \mathrm{mmHg}$, which increased to $27.24 \pm$ $10.48 \mathrm{mmHg}$ after injection. There was no significant change in any AS-OCT parameter after IVI (paired samples t-test) (Table 2).

\begin{tabular}{lcccc}
\multicolumn{1}{c}{ Parameter } & Mean & SD & 95\% Cl & p-Value \\
Nasal AOD500 $(\mathrm{mm})$ & 0.0002 & 0.1166 & $-0.0433-0.0437$ & 0.99 \\
Nasal AOD750 $(\mathrm{mm})$ & -0.0264 & 0.1860 & $-0.0958-0.0430$ & 0.44 \\
Nasal TISA500 $\left(\mathrm{mm}^{2}\right)$ & 0.0020 & 0.0333 & $-0.0104-0.0144$ & 0.75 \\
Nasal TISA750 $\left(\mathrm{mm}^{2}\right)$ & 0.0197 & 0.0990 & $-0.0173-0.0567$ & 0.29 \\
Nasal SSA (degrees) & -0.0233 & 9.0628 & $-3.4074-3.3607$ & 0.99 \\
Temporal AOD500 $(\mathrm{mm})$ & 0.0394 & 0.1427 & $-0.0138-0.0926$ & 0.14 \\
Temporal AOD750 $(\mathrm{mm})$ & 0.0091 & 0.1834 & $-0.0594-0.0776$ & 0.79 \\
Temporal TISA500 $\left(\mathrm{mm}^{2}\right)$ & 0.0107 & 0.0537 & $-0.0093-0.0307$ & 0.29 \\
Temporal TISA750 $\left(\mathrm{mm}^{2}\right)$ & 0.0152 & 0.0874 & $-0.0174-0.0478$ & 0.35 \\
Temporal SSA (degrees) & 2.5931 & 11.2709 & $-1.6941-6.8803$ & 0.23
\end{tabular}

Table 2: Change in anterior segment OCT parameters after intravitreal injection. AOD - angle opening distance; TISA - trabecular-iris space area; SSA - scleral spur 
angle; SD - standard deviation; 95\% Cl - 95\% confidence interval. P-values obtained with paired samples t-test.

Neither axial length, phakic status nor anterior chamber depth were significant predictors of change on either univariate or multivariate linear regression analysis for any parameter. The results were validated with excellent intraclass correlation coefficient (>0.8) for almost all the parameters (Table 3 ).

$\begin{array}{lcc}\text { Parameter } & \text { Average measures } & \mathbf{9 5 \%} \mathbf{C l} \\ \text { Nasal AOD500 } & 0.9 & 0.625-0.975 \\ \text { Nasal AOD750 } & 0.899 & 0.592-0.975 \\ \text { Nasal TISA500 } & 0.819 & 0.308-0.954 \\ \text { Nasal TISA750 } & 0.919 & 0.668-0.98 \\ \text { Nasal SSA } & 0.922 & 0.699-0.98 \\ \text { Temporal AOD500 } & 0.84 & 0.338-0.961 \\ \text { Temporal AOD750 } & 0.79 & 0.2-0.947 \\ \text { Temporal TISA500 } & 0.685 & -0.355-0.923 \\ \text { Temporal TISA750 } & 0.811 & 0.248-0.953 \\ \text { Temporal SSA } & 0.887 & 0.547-0.972\end{array}$

Table 3: Intraobserver reproducibility of the angle measurements as determined by intraclass correlation coefficient. AOD - angle opening distance; TISA - trabeculariris space area; SSA - scleral spur angle; SD - standard deviation.

Though some cases of angle closure after IVI have been reported, our results suggest that IVI does not significantly alter the anterior chamber angle, accounting for phakic status, axial length and anterior chamber depth. This is in keeping with Alkin et al, who showed that AS-OCT parameters of the nasal angle were not significantly altered in phakic, undilated pupils with either $0.05 \mathrm{~mL}$ or $0.1 \mathrm{~mL} I \mathrm{VIs}$ (3). 
To our knowledge, ours is the first study to assess change in dilated pupils and those who are pseudophakic in either the temporal or nasal angles.

Our results contrast those published by another group with similar patient numbers (4). However, that study did not perform an intraclass correlation coefficient to determine internal validity and imaged patients in undilated scotopic conditions, which is not generalisable to a clinical environment. Only 4 out of 12 parameters tested were statistically significant, with a weak correlation of anterior chamber depth and IOP change $\left(R^{2}=0.53\right)$.

Limitations of our study include a lack of ethnic diversity (with only 3 Asian patients) and no assessment of the superior and inferior angles due to limitations with image quality. However, the reproducibility of measurements in the temporal and nasal angles is better than superior and inferior (5).

In summary, our results reflect a daily practice setting and demonstrate that AS-OCT parameters in either the temporal or nasal angle are not significantly altered by IVI, accounting for phakic status, axial length and anterior chamber depth. 


\section{REFERENCES}

1. van der Reis MI, La Heij EC, De Jong-Hesse Y, Ringens PJ, Hendrikse F, Schouten JSAG. A systematic review of the adverse events of intravitreal antivascular endothelial growth factor injections. Retina Phila Pa. 2011 Sep; 31(8): 1449-69.

2. Nolan WP, See J L, Chew PTK, Friedman DS, Smith SD, Radhakrishnan S, et al. Detection of primary angle closure using anterior segment optical coherence tomography in Asian eyes. Ophthalmology. 2007 J an; 114(1):33-9.

3. Alkin Z, Perente I, Altan C, Konstantinidis A, Ozkaya A, Yuksel K, et al. Changes in anterior segment morphology after intravitreal injection of bevacizumab and bevacizumab-triamcinolone acetate combination. Eur J Ophthalmol. 2013 Aug;23(4):504-9.

4. Wen JC, Cousins SW, Schuman SG, Allingham RR. DYNAMIC CHANGES OF THE ANTERI OR CHAMBER ANGLE PRODUCED BY INTRAVITREAL ANTI-VASCULAR GROWTH FACTOR INJ ECTIONS. Retina Phila Pa. 2016 Oct; 36(10): 1874-81.

5. Radhakrishnan S, See J, Smith SD, Nolan WP, Ce Z, Friedman DS, et al. Reproducibility of anterior chamber angle measurements obtained with anterior segment optical coherence tomography. Invest Ophthalmol Vis Sci. 2007 Aug; 48(8):3683-8. 


\section{University Library}

\section{- M M N E R VA A gateway to Melbourne's research publications}

Minerva Access is the Institutional Repository of The University of Melbourne

Author/s:

Atik, A;Wickremasinghe, SS;Sandhu, SS;Ang, GS

Title:

Intravitreal injection does not change anterior chamber morphology on anterior segment optical coherence tomography.

Date:

2020-07

\section{Citation:}

Atik, A., Wickremasinghe, S. S., Sandhu, S. S. \& Ang, G. S. (2020). Intravitreal injection does not change anterior chamber morphology on anterior segment optical coherence tomography.. Clin Exp Ophthalmol, 48 (5), pp.711-713. https://doi.org/10.1111/ceo.13752.

Persistent Link:

http://hdl.handle.net/11343/275574 